\title{
Health Seeking Behaviour of Afar Pastoral Community
}

\author{
Suadiq Sufian Ali, Bisrat Tekle Woldearegai
}

\begin{abstract}
Community level health seeking behavior needs investigation since community plays either protective or pathogenic role to health. This study, therefore, intended to examine the health seeking behavior of Afar using a community based cross-sectional survey design. The survey employed both quantitative and qualitative methods to collect relevant data. The findings revealed that a substantial number of participants have had misconceptions and/or erroneous knowledge about the causes and symptoms of illnesses. Besides, most of the participants preferred treatment service from modern health care institutions. Their choice is significantly associated with age and level of education. Moreover, various factors including cost, distance, attitude toward health, decision-making power on health, perceived satisfaction, social capital and socio-religious behaviour affect the utilization of available health care services. In general, the findings implied the presence of a positive health seeking behavior among Afar that can be further strengthened with interventions. The interventions should address the misconceptions about causes/symptoms of illnesses and promote appropriate hierarchy of resort to the utilization of available health care services.
\end{abstract}

Keywords : health seeking behavior, illness, diseases, symptoms, causes.

\section{INTRODUCTION}

T hroughout history, people have tended to realize health problems from the perspectives of their own particular culture and society's perspectives. In most traditional societies, before modern medical profession started to claim the provision of health care services monopolistically, health care responsibilities are placed upon the patient's family or her/his community. As a larger cultural group, each community has its own particular view of the world that influences health (Helman, 2000). The culture of each community has particular beliefs about disease causation, symptoms and treatments. Therefore, understanding how communities interpret their symptoms, how they define their illness, how they perceive medical system and how they access to health care services is tremendously important. To realize all these, enquiring community's health seeking behavior using a sociological point of is apparently necessary.

Health seeking behavior as a process refers to two complimentary behaviors: health behavior and illness

Revised Manuscript Received on July 22, 2019

Suadiq Sufian Ali, Department of Sociology, Wollo University, Ethiopia, PhD Scholar in Sociology, Kalinga Institute of Industrial Technology, Bhubaneswar, Odisha, India

Bisrat Tekle Woldearegai, Department of Sociology and Social Work, Arsi University, Ethiopia, PhD Scholar in Sociology, Kalinga Institute of Industrial Technology, Bhubaneswar, Odisha, India

behavior. The former denotes all activities undertaken by a person who believes himself or herself to be healthy for the purpose of preventing diseases. Meanwhile, the later refers to the activities undertaken by a person who feels ill in order to define that illness and seek respite from it (Cockerham, 2007). Therefore, health-seeking behavior is not an isolated event decided by individuals focusing merely on their self-interest. Rather, it is part and parcel of individuals', families' or community's identity, which involves a combination of social, personal, cultural and experiential factors. This entails that individuals and communities respond to health in a manner consistent with their culture, norms and values (MacKian, 2003).

The study of health seeking behavior helps to understand the utilization of health care services in a specific socio-cultural, economic and demographic environment. In this respect, Helman (2000) noted, "The relationship between social conditions and factors that influence health has long been a major research interest of mankind. Health is often interwoven with the social, religious, political and economic organization of the society". The development health seeking behavior studies highlights that social science inputs are crucial to understand community's beliefs and behaviors. According to Wilkinson (1996), the turning point into which a shift to social science inputs has been made since "our knowledge of people's socially and economically structured life processes that exerts the most powerful influences on health in the modern world turns the exploration of health into a social science. Perhaps, the fact that health seeking behavior is 'not even mentioned' in widely used medical textbooks reflects many health seeking behavior studies need social science inputs".

In line with the aforementioned research interest, this study intended to assess the health seeking behavior of Dubti community of Afar region, Ethiopia. Afar Region with finger counted hospitals, fewer health centers and in general limited health services coverage represented almost the lowest level of health care service in the country. The devastating health condition of pastoralists obliged anyone concerned to have epidemiological evidence based information for making appropriate decision that potentially respite pastoralists from life threatening illnesses (Dubale, 2005). However, studies assessing health-seeking behavior are scanty in Ethiopia in general and the pastoralist's region in particular. Therefore, the current study attempted to examine the health seeking behavior of Afar pastoral communities with a sociological eye to describe the causes, symptoms and treatment of illnesses, and pointing out factors affecting health care service utilization. 


\section{RESEARCH METHOD}

The study employed a cross-sectional survey design that employed both qualitative and quantitative methods. Mixed research method provides a broad understanding of the process of health seeking behavior through triangulation. In fact, the pattern of health seeking behaviour is often context specific and requires an in-depth qualitative investigation (Ngom, et al., 2000). Yet, the inherent feature of the qualitative method (high degree of subjectivity, restrictedness, vagueness etc.,) may create certain gaps. To compensate this gap, quantitative method was also used. More to the point, relevant information was gathered through household survey and in-depth interview methods. For the purpose of collecting quantitative data, a door-to-door household survey was carried out on a total of 100 heads of the household using structured questionnaires.

The sample size was determined based on the following given information: (1) the Bare Foot Initiative estimated that about $6 \%$ of the Afar population has access to appropriate health care services. Using this figure, the calculation of the sample size assumed that the same amount of the study population has access to appropriate health care services; (2) $95 \%$ confidence level has been taken and (3) $5 \%$ of desired precision has been assumed. Then, based on the following formula, a sample size (n) of 87 respondents has been computed.

$$
\begin{aligned}
& \mathrm{n}=\frac{(\mathrm{Z \alpha} / \underline{2})^{2} \mathrm{P}(1-\mathrm{P})}{\mathrm{d}^{2}} \\
& \mathrm{n}=\frac{(1.96)^{2} \times 0.06(1-0.06)}{(0.05)^{2}} \\
& \mathrm{n}=86.67 \approx 87
\end{aligned}
$$

Where, " $n$ " is the total sample size, " $\alpha "=0.05$, " $\mathrm{Z} \alpha / 2$ " 1.96 , " $Z$ " is the confidence limits of the survey result which is 1.96 , " $P$ " is the proportion of Dubti community who has an access to appropriate health care services $(6 \%)$ and $d$ is the sampling error tolerated at 0.05 . For non - response, $15 \%$ (13) of the sample size was included. In sum, there was a total sample size of 100 participants.

On the other hand, in-depth interviews were conducted with selected household heads, government officials and health workers to collect detail information.

\section{RESULT}

\section{Perception of Causes, Symptoms and Treatment of Illness Causes of Illness}

Perception of causes of illness determines health-seeking behavior. Several causes of illness were reported in the current study. Among other things, participants cited improper eating habit, malnutrition, contamination of food, carelessness, accident, germ, curse of God, committing sin, unsafe sex, lack of hygiene and sanitation, witchcraft intervention, evil eye, hot weather condition, bad smelling from modern health institutions, lack of adequate knowledge about good health, water pollution, harmful traditional practices and addiction as the leading causes of illness. The finding implies that all types of illness causation explanation have certain relevance in the study community. Thus, the causes of illness could be attributed into one of the four explanation of illness causation: within the individual, in the natural world, in the social world, and in the super natural world (Helman, 2000).

In addition, the survey result showed that germs (35\%), malnutrition $(26 \%)$ and curse of God $(16 \%)$ as the most frequently cited causes of illness. Witchcraft involvement (5\%) and other possible causes (3\%) are also reported. Here, it is important to underscore that participants who reported witchcraft involvement as the main cause of illness are found within the age group 20-35. Perhaps this suggests that interpersonal malevolence is high among the young participants. Therefore, somehow, the finding is consistent with Helman's (2000) position that asserts traditional small-scale societies often blame other people for one's ill health.

As the cause of illness is subjected to change through time and education, a chi- square test was conducted to see any significant association. To this end, participants' level of education and their perceived knowledge about the causes of illness were cross tabulated. As shown in table 1 , no statistically significant association found between respondents' perceived knowledge about causes of illness and their levels of education $(p=0.219)$. This could imply individuals learn the causes of illness from experience with the illnesses. Moreover, the test revealed that the association between perceived causes of illness and age is insignificant ( $p=0.377)$, and thereby highlighting that various age groups have shared similar piece of information about causes of illness through traditional channel of communication "Dagu”. As informants explained, Dagu is a long standing tradition by which Afar people communicate about important events such the occurrence of epidemic, and exchange information regarding the location of water, pasture etc. 
Table- I: Perception about the Causes of Illness

\begin{tabular}{|c|c|c|c|c|c|c|c|c|}
\hline \multirow[t]{3}{*}{ Characteristics } & \multicolumn{7}{|c|}{ Causes of Diseases } & \multirow{3}{*}{ P-Value } \\
\hline & $\left.\begin{array}{l}\text { Germ } \\
(\mathrm{n}=35\end{array}\right)$ & $\begin{array}{l}\text { Witchcraft } \\
\text { Involveme } \\
\mathrm{nt}(\mathrm{n}=5)\end{array}$ & $\begin{array}{l}\text { Hot } \\
\text { Weathe } \\
\mathrm{r} \\
(\mathrm{n}=11)\end{array}$ & $\begin{array}{l}\text { Evil } \\
\text { Eye } \\
(n=4)\end{array}$ & $\begin{array}{l}\text { Curse of } \\
\text { God } \\
(n=16)\end{array}$ & $\begin{array}{l}\text { Malnutritio } \\
\mathrm{n} \\
(\mathrm{n}=26)\end{array}$ & $\begin{array}{l}\text { Other } \\
(n=3)\end{array}$ & \\
\hline & $35 \%$ & $5 \%$ & $11 \%$ & $4 \%$ & $16 \%$ & $26 \%$ & $3 \%$ & \\
\hline \multicolumn{9}{|l|}{ Educational status } \\
\hline $\begin{array}{ll}\text { No } & \text { formal } \\
\text { education } & \end{array}$ & $\begin{array}{l}24.0 \\
\%\end{array}$ & $8.0 \%$ & $4.0 \%$ & $8.0 \%$ & $36.0 \%$ & $20.0 \%$ & $0.0 \%$ & \multirow{4}{*}{0.219} \\
\hline Primary education & $\begin{array}{l}37.0 \\
\%\end{array}$ & $5.0 \%$ & $16.0 \%$ & $0.0 \%$ & $16.0 \%$ & $16.0 \%$ & $\begin{array}{l}11.0 \\
\%\end{array}$ & \\
\hline $\begin{array}{l}\text { Secondary } \\
\text { education }\end{array}$ & $\begin{array}{l}53.0 \\
\%\end{array}$ & $0.0 \%$ & $5.0 \%$ & $0.0 \%$ & $5.0 \%$ & $32.0 \%$ & $6.0 \%$ & \\
\hline Above Grade 12 & $\begin{array}{l}40.0 \\
\%\end{array}$ & $0.0 \%$ & $20.0 \%$ & $\begin{array}{l}10.0 \\
\%\end{array}$ & $0.0 \%$ & $30.0 \%$ & & \\
\hline \multicolumn{9}{|l|}{ Age in years } \\
\hline $20-35$ & $60 \%$ & $100 \%$ & $63.6 \%$ & $50 \%$ & $25.0 \%$ & $66.7 \%$ & $\begin{array}{l}58.0 \\
\%\end{array}$ & \multirow{5}{*}{0.377} \\
\hline $36-50$ & $\begin{array}{l}31.4 \\
\%\end{array}$ & $0.0 \%$ & $18.2 \%$ & $25 \%$ & $43.8 \%$ & $15.4 \%$ & $\begin{array}{l}33.3 \\
\%\end{array}$ & \\
\hline $51-65$ & $5.7 \%$ & $0.0 \%$ & $9.1 \%$ & $0.0 \%$ & $12.5 \%$ & $7.7 \%$ & $0.0 \%$ & \\
\hline $66-80$ & $0.0 \%$ & $0.0 \%$ & $9.1 \%$ & $0.0 \%$ & $12.5 \%$ & $11.5 \%$ & $0.0 \%$ & \\
\hline Above 80 & $2.9 \%$ & $0.0 \%$ & $0.0 \%$ & $25 \%$ & $6.3 \%$ & $0.0 \%$ & $3.0 \%$ & \\
\hline
\end{tabular}

\section{Symptoms of illness}

Perception about symptoms of illness determines treatment choice behaviour and action taken in the health care seeking behavior. Participants identified diversified symptoms of illness including fever, talking alone, joint pain, malaria, anger, stress, depression, fatigue, headache, loss of appetite, vomiting, thinness, 'Qnduffe'. Qunduffe is a symptom of skin diseases reported by most of the participants. According to informants, this symptom occurs due to hot climatic condition. Afar people have occupied the hottest inhabited area on earth with an average temperature of $46^{\circ} \mathrm{C}$. Thus, they have demonstrated a surprising resilient capacity for long and short-term crisis (Helmand, 2015).

Participants were asked whether they could define their symptoms in modern health institutions. As data obtained from the in-depth interview showed, some failed to mention their symptoms of illness correctly. Other mentions different diseases as symptoms of illness. There is also a tendency to use symptoms and diseases interchangeably. For instance, a woman participant cited malaria as symptom of illness rather than as disease. She said, "It [malaria] is a symptom of illness, weaknesses and disorders in our body. Had it been our body strong enough to resist, it would not have been threatened by an insect [anopheles mosquito] that has no even a size offly."

Modern health professionals reported their clients failed to say symptoms of illness correctly because of communication barrier existed between the health professionals and the client. In this regard, Dubti Hospital medical director disclosed, "patients were not able to communicate their symptoms of

illness using clear language to health professionals. Hence, we cannot understand the meaning of their various nonspecific complaints." He added that the communication barrier affects the health care service utilization system especially when the patients and health professionals speak two different languages. Unfortunately, as observation indicated, most of the health care professionals were not native Afar and could not speak Qafar-af though majority of the patients were native Afar who speak only Qafar-af. In such circumstances, communicating about symptoms of disease is hardly possible. Sometimes, even when there is a translator, effective communication between the health professional and the patient became difficult. To handle this problem, of course, health professionals heavily relied on all available diagnostic tests. A health professional in Dubti hospital has the following to say:

Most of the people who came here [Dubti hospital] do not know how to describe their specific symptoms of illness and locate which parts of their body is affected. Usually, they (patients) link their symptoms of illness to specific organs, especially to their heart, stomach and head. Hence, defining diseases based on patients' information becomes a challenging task for us. This is why; we resort to different diagnostic tests.

The challenge faced by Dubti Hospital is a reflection of the shadow of uncertainty in relation to patients' description of symptoms. 
Nonetheless, health need is often defined/provided according to patients' pronunciation of symptoms as a cross check mechanism is not available. There is scarcity of multiple diagnostic tests in the study area due to limited health care facilities. Consequently, a greater probability of mismatch between diseases and prescribed medicines could be observed when the patient reported his/her symptoms wrongly.

\section{Choice of Health Care Institutions for Treatment}

Several factors influenced the choice of health care institutions. These include beliefs about the causes of diseases; trust on the cure of medication, availability of the required medicine, cost of health care services, the influence of significant others, attitude towards health care services and socio-cultural factors that govern interpersonal relationship. Depending on these factors, patients sought health care services from traditional or modern health institutions. Sometimes, they preferred only self-medication at home.

Health care seeking behavior, to a large extent, relied on people's understanding and interpretation of the causes of their illness. For instance, a mother of six children reported, "If I have an idea my child might have been attacked by evil eye, I would have taken him to exorcist. But, if he had suffered from diarrhea, I would have taken him to a nearby health post." This entailed that when people admit the bio-medical theory of disease causation, their effort to the search for a cure to a disease will be different from the effort of those who attribute the disease to a magico-religious model.

The participants were asked about their choice of health care services to maintain/resort to health. For majority of them (71\%) modern medication was their first choice. On the other hand, $16 \%$ of them preferred to traditional medication. The remaining $3 \%$ chose self medication. Meanwhile, about one-tenth (10\%) sought both traditional and modern medications simultaneously or immediately one after the other due to uncertainty. Table 2 demonstrated that the choice of medication cross tabulated with socio-demographic and economic characteristics of the respondents. It was observed that age and educational status of the respondents have significant association with the choice of medication with an equal $p$-value of 0.02 . With advancing age, more people may choose traditional medication. Along similar lines, with increasing level of education more people prefer to modern medication. The table also revealed that no significant association found between other socio demographic characteristics (sex, ethnicity and marital status of the respondent with $p$-values of $0.115,0.341$ and 0.402 respectively) and choice of medication.

Table II: Respondents' choice of treatment services

\begin{tabular}{|c|c|c|c|c|c|c|c|c|c|c|}
\hline \multirow{3}{*}{$\begin{array}{l}\text { Socio-demographic } \\
\text { and economic } \\
\text { characteristics }\end{array}$} & \multicolumn{9}{|c|}{ Choice of medication } & \multirow[t]{3}{*}{$P$-value } \\
\hline & \multicolumn{3}{|c|}{$\begin{array}{c}\text { Self } \\
\text { medication }\end{array}$} & \multicolumn{2}{|c|}{\begin{tabular}{|l|} 
Modern \\
Medication \\
\end{tabular}} & \multicolumn{2}{|c|}{$\begin{array}{l}\text { Traditional } \\
\text { medication }\end{array}$} & \multicolumn{2}{|c|}{$\begin{array}{l}\text { Traditional and } \\
\text { modern }\end{array}$} & \\
\hline & $\mathbf{N}=$ & $=\mathbf{3}$ & $\%=3$ & $\mathrm{~N}=71$ & \begin{tabular}{l|l}
$\%=71$ \\
\end{tabular} & $N=16$ & $\%=16$ & $\mathrm{~N}=10$ & $\%=10$ & \\
\hline \multicolumn{11}{|l|}{ Sex } \\
\hline Male & 3 & & 4.5 & 43 & 65.2 & 14 & 21.2 & 6 & 9.1 & \multirow[b]{2}{*}{0.115} \\
\hline Female & 0 & & 0 & 28 & 82.4 & 2 & 5.9 & 4 & 11.8 & \\
\hline \multicolumn{11}{|l|}{ Age in years } \\
\hline $20-35$ & 1 & & 1.7 & 47 & 81 & 4 & 6.9 & 6 & 10.3 & \multirow{5}{*}{0.02} \\
\hline $36-50$ & 2 & & 7.7 & 16 & 61.5 & 6 & 23.1 & 2 & 7.7 & \\
\hline $51-65$ & 0 & & 0 & 5 & 71.4 & 2 & 28.6 & 0 & 0 & \\
\hline $66-80$ & 0 & & 0 & 2 & 33.3 & 4 & 66.7 & 0 & 0 & \\
\hline$>80$ & 0 & & 0 & 1 & 33.3 & 0 & 0 & 2 & 66.7 & \\
\hline \multicolumn{11}{|l|}{ Ethnicity } \\
\hline Afar & 3 & 4.1 & 4 & 9 & 67.5 & 15 & 20.5 & 6 & 8.2 & \multirow{5}{*}{0.341} \\
\hline Tigre & 0 & 0 & 6 & & 100 & 0 & 0.0 & 0 & 0 & \\
\hline Amhara & 0 & 0 & 9 & & 81.8 & 1 & 9.1 & 1 & 9.1 & \\
\hline Oromo & 0 & 0 & 5 & & 62.5 & 0 & 0.0 & 3 & 37.5 & \\
\hline Others & 0 & 0 & 2 & & 100 & 0 & 0.0 & 0 & 0 & \\
\hline \multicolumn{11}{|l|}{ Marital status } \\
\hline Unmarried & 1 & 8.3 & 9 & & 75 & 2 & 16.7 & 0 & 0 & \multirow{4}{*}{0.402} \\
\hline Married & 2 & 2.8 & 5 & 2 & 72.7 & 12 & 16.7 & 6 & 8.3 & \\
\hline Widow/er & 0 & 0 & 8 & & 72.7 & 1 & 9.1 & 2 & 18.2 & \\
\hline Divorced & 0 & 0 & 2 & & 40 & 1 & 20.0 & 2 & 4 & \\
\hline \multicolumn{11}{|l|}{ Educational status } \\
\hline No formal education & 0 & 0 & 1 & 0 & 40 & 10 & 40.0 & 5 & 20 & \multirow[b]{4}{*}{0.02} \\
\hline Primary education & 0 & 0 & 1 & 3 & 68.4 & 2 & 10.5 & 4 & 21.4 & \\
\hline Secondary education & 2 & 10.5 & 1 & 5 & 78.9 & 1 & 5.3 & 1 & 5.3 & \\
\hline Above grade 12 & & 0 & 1 & 9 & 95 & 1 & 5.3 & 0 & 0 & \\
\hline
\end{tabular}




\begin{tabular}{|l|l|l|l|l|l|l|l|l|l|}
\hline Income per month & 0 & 0 & 16 & 64 & 7 & 28 & 2 & 8 & \\
\hline$<1000$ & 0 & 0 & 24 & 85.7 & 2 & 7.1 & 2 & 7.1 & \multirow{2}{*}{0.110} \\
\hline $1000-2000$ & 0 & 0 & 10 & 76.9 & 1 & 7.7 & 2 & 15.4 & \\
\hline $2001-3000$ & 0 & 0 & 6 & 100 & 0 & 0 & 0 & 0 & \\
\hline$>3000$ & 3 & 3 & 15 & 53.5 & 6 & 21.4 & 4 & 14.3 & \\
\hline Do not know & &
\end{tabular}

\section{RESULT AND CONCLUSION}

In the study community, there were misconceptions about causes and symptoms of certain illnesses. The communication barrier between modern health professionals and patients hinder patients to define their symptoms of illness to physicians. Yet, most of the people sought treatment services from modern health care services. This implied the presence of a positive health seeking behavior among Afar that can be further strengthened with the help of interventions. Such interventions are mainly useful to reduce misconceptions about causes/symptoms of illnesses, and promote appropriate hierarchy of resort in the utilization of health care services.

\section{REFERENCES}

1. Cockerham, W. C. (2007). Medical sociology. Routledge.

2. Dubale, T. (2005). Department Of Community Health Faculty of Medicine Addis Ababa University (Doctoral dissertation, School of Graduate Studies, Addis Ababa University).

3. Helman, C. (2007). Culture, health and illness. CRC press.

4. Helmand, J. (2015). Afar Resilience Study Feinstein International Center (Tufts University) and Afar Region Disaster Prevention, Preparedness and Food Security Coordination Office, Afar Regional State, Ethiopia. WP 2015: 6

5. MacKian, S. (2003). A review of health seeking behaviour: problems and prospects. Health Systems Development Programme.

6. Ngom, P., Binka, F. N., Phillips, J. F., Pence, B., \& Macleod, B. (2001). Demographic surveillance and health equity in sub-Saharan Africa. Health Policy and Planning, 16(4), 337-344.

7. The Barefoot initiative (2009). http://www.barefootinitiative.org/

8. Wilkinson, R. (1996). Unhealthy Societies: the Afflictions of Inequality, London: Routledge 